\title{
Outcomes and Quality of Life Following Skull Base Surgery
}

\author{
John R. de Almeida $\cdot$ Allan D. Vescan
}

Published online: 24 August 2013

(C) Springer Science+Business Media New York 2013

\begin{abstract}
Treatment goals following skull base surgery have shifted over the last decade to improving functional outcomes and quality of life. Given the intimacy of skull base tumors to vital structures, the potential for morbidity, functional impairments, and a decline in quality of life after surgery is possible. The endoscopic endonasal approach may have potential functional outcome and quality of life benefits for select tumors and in select anatomic locations of the skull base compared to open approaches. Diseasespecific quality of life instruments such as the Skull Base Inventory and the Anterior Skull Base have been created to compare quality of life between these approaches. Large multi-centered prospective trials are needed to better study the potential benefits of the endoscopic endonasal approach.
\end{abstract}

Keywords Skull base surgery · Endoscopic · Open · Outcomes · Quality of life

\section{Introduction}

Over the last few decades, treatment goals of skull base surgery have changed, with a new emphasis on minimizing morbidity and maximizing quality of life. The proximity of these tumors to brain, cranial nerves, neurovascular

J. R. de Almeida $(\square)$

Toronto General Hospital, 200 Elizabeth Street, 8N-881,

Toronto, ON M5G 2C4, Canada

e-mail: john.dealmeida@uhn.ca

A. D. Vescan

Mount Sinai Hospital, 600 University Ave, Room 401, Toronto, ON M5G 1X5, Canada

e-mail: avescan@mtsinai.on.ca structures, the orbit, and the sinonasal cavity may result in collateral damage by the tumor itself or by its treatment. Deficits incurred can impact how the patient senses and interacts with his/her environment, which in turn can have a significant impact on quality of life. Improved diagnostic imaging modalities, the use of image guidance systems, targeted delivery of radiotherapy, and new surgical approaches such as the endoscopic endonasal approach may all have potential implications with regards to improving quality of life.

The endoscopic endonasal approach has been labeled as "minimally invasive" with the implication that it is not associated with the same morbidity profile as open approaches. This may be true in certain instances. For example, traditional facial disassembly approaches or lateral transcranial approaches to the clivus have arguably been supplanted by the endonasal approach. In other cases, such as in the treatment of sinonasal malignancies, the "minimally invasive" description may be a misnomer and perhaps a more appropriate adage would be "incision sparing".

The morbidity following endoscopic endonasal surgery likely represents a change in the morbidity profile from traditional "open" transcranial or transfacial approaches and not necessarily an exemption from morbidity. Proponents of the endonasal approach contend that the lack of brain retraction may result in improved neurocognitive outcomes compared to open surgery. Detractors of the approach suggest that it renders the nose functionally crippled. Careful delineation of the relevant outcomes such as nasal, neurological, and visual outcomes following surgery and rigorous measurement of quality of life using appropriate disease-specific or generic quality of life instruments are needed to understand the full impact of surgery. 


\section{Nasal Outcomes}

Interest in measuring nasal outcomes has spawned in the advent of endoscopic endonasal approaches to the skull base. Extensive dissection of anatomic modules to create corridors for surgical access can impair normal nasal physiology and mucociliary flow, resulting in significant nasal crusting and alterations in olfaction. Although open approaches likely have similar sequelae in the nose, these outcomes have not been extensively studied in this population, perhaps because of other clinically significant morbidities incurred by open approaches.

The mucosal preserving philosophy of endoscopic sinus surgery does not necessarily apply during endoscopic skull base surgery. The surgical philosophy of adequate access and the creation of surgical corridors trump mucosal preservation. As such, patients suffer from nasal crusting (98\%), nasal discharge (46\%), loss or decreased smell (10\%), and decreased nasal airflow (5\%) among other symptoms, as shown in a prospective study [ $1 \bullet]$. Consequently, the normal nasal physiology and mucociliary flow is altered. Alobid et al. [2] investigated the physiologic repercussions of endonasal surgery on mucociliary flow and found that patients with endonasal approaches have prolonged saccharin transit times, suggesting an impairment.

In general, the effects of endoscopic endonasal surgery on sinonasal quality of life seem transient, with temporary deterioration followed by significant improvements at 1 year after surgery [3]. Nasal crusting is particularly troublesome shortly after surgery but gradually resolves. We showed that $50 \%$ of patients are crust-free at 101 days after surgery [1•]. Patients who had more extensive dissections had longer crusting times and those with septal flaps had a trend to longer times, although not statistically significant $[1 \cdot 3]$. One strategy to reduce the crusting associated with septal flaps is to harvest a mucosal graft from the middle turbinate (which is usually resected for access) and place it over the denuded septum [4]. The decision to harvest a septal flap is typically made at the beginning of the procedure. For transsellar procedures, it is often unclear whether a septal flap is needed until later in the case if, for example, a cerebrospinal fluid (CSF) leak is identified. To avoid unnecessary septal flaps, some surgeons have adopted the use of a rescue flap whereby the vascular pedicle of the posterior septal branch of the sphenopalatine artery is preserved with its surrounding mucosa from the choana to the sphenoid ostium. The flap is only raised at the termination of the procedure if needed [5, 6]. Another option is to harvest the flap, store it in the nasopharynx, and lay the flap back into its native position on the septum if it is not needed. These methods may reduce long-term crusting of the nasal septum, decrease hospital visits for debridement, and improve the nasal airway.

Patient-reported hyposmia or anosmia after surgery also seems to follow the trend of a temporary decline followed by a gradual improvement. Using a disease-specific quality of life questionnaire, one group showed a reduction in smell and taste at 6 weeks after endoscopic pituitary surgery, with a gradual return to baseline at 1 year [7]. Similar results were found with patients undergoing endoscopic approaches for non-pituitary lesions. These results were corroborated by Alobid et al. [2], who showed that patients experienced a reduction in their sense of smell using the Barcelona Smell Test (BAST-24). This loss of smell is more pronounced in patients undergoing more expanded approaches. However, in patients who have had endoscopic transsphenoidal surgery with a middle turbinate sacrificing approach, one group showed no difference in sense of smell comparing patients pre- and post-operatively using the University of Pennsylvania Smell Identification Test (UPSIT), suggesting a need for further larger-scale study [8•]. Choice of reconstructive methods also seems to influence olfaction. The use of the nasoseptal flap has been associated with poor smell and quality of life post-operatively $[9,10 \bullet]$. To help minimize the risk of hyposmia following nasoseptal flap harvest, our practice is to leave a cuff of at least $1 \mathrm{~cm}$ of mucosa along the superior septum to prevent damage to the olfactory mucosa.

There is a relative dearth of literature pertaining to sinonasal outcomes for open skull base approaches. However, studies do suggest that both anosmia and nasal crusting are also a significant problem in this patient population, with roughly two-thirds of patients suffering from both deficits [11]. In one study of patients who had facial translocation approaches for skull base tumors, the most common problems were nasal congestion and crusting [12]. However, these problems were outweighed by other complications, such as plate exposures and palatal fistulas, again emphasizing the difference in morbidity profiles between open and endoscopic approaches.

\section{Neurologic Outcomes}

Perhaps the biggest purported advantage of endoscopic approaches is the avoidance of significant brain retraction. Kassam et al. [13•] reported their experience for 800 patients who underwent endoscopic endonasal approaches and found $1.8 \%$ had neural injury, including 4 cases $(0.5 \%)$ of hemiparesis, and 6 cases $(0.8 \%)$ of transient and 4 cases $(0.5 \%)$ of permanent cranial neuropathy. In a follow-up study reporting outcomes for 1,000 patients, the same group reported a rate of meningitis of $1.8 \%$ and a 
CSF leak rate of $14 \%$ [14•]. In a multivariable analysis, risk factors for development of infection included male sex, history of previous surgery (transcranial or endonasal), more complex surgeries (intradural), the presence of external ventricular drain or ventriculo-peritoneal shunt at the time of surgery, or post-operative CSF leaks. CSF leaks were present in 13 of 18 patients who developed meningitis. Avoiding these leaks with sound reconstructions is paramount in avoiding the neurologic sequalae associated with intracranial infections.

Patients with skull base tumors treated with open anterior craniofacial resections seem to have similar meningitis and CSF leak rates. Two prior studies with open approaches report meningitis rates between 2 and $4.8 \%$ [15, 16]. Similarly, CSF leak rates after open approaches are comparable to endoscopic series. Leak rates of the anterior cranial base have been reported between 13 and $29 \%$ [17, 18], although one study reported a dramatic decrease in leak rate to $5 \%$ with the use of free tissue transfer [19]. In a large international collaborative study of 1,193 patients who had traditional open approaches with anterior craniofacial resectons, $16.2 \%$ had CNS-related complications [20].

Tumor location likely also influences the development of neurologic sequelae. For example, clival tumors are readily accessible with endoscopic techniques, whereas approaching these lesions with open techniques often requires significant brain retraction and manipulation or circumventing important neurovascular structures. A recent study comparing outcomes from the same institution showed that $6 \%$ of patients with clival chordomas had worsening neurologic status (hemiparesis) after undergoing endoscopic approaches compared to $33 \%$ after open approaches (hemiparesis, brainstem compression, cranial neuropathies) [21]. This variability in outcomes by tumor location represents a challenge in comparing surgical approaches.

\section{Visual Outcomes}

Many patients with skull base pathology will have visual deterioration as a presenting complaint. Our group compared outcomes of those undergoing endoscopic and open approaches in 138 patients, and patients with endoscopic approaches have significantly fewer visual complaints postoperatively in comparison to those with open approaches [22]. This is likely due to a selection bias of patients with pre-operative visual symptoms and orbital invasion requiring open approaches. However, even after adjusting for confounders such as tumor extent and pre-operative symptoms, open approaches were still associated with more post-operative visual symptoms. Kassam et al. [13•] noted only 4 cases of visual deterioration $(0.5 \%)$ from their first 800 cases and 7 cases of delayed visual deterioration all of which resolved after the etiologic process was addressed. Orbital complications following open craniofacial resection, on the other hand, were reported in $1.7 \%$ of patients of 1,193 patients [20].

Much like other outcomes in skull base surgery discussed earlier, visual outcomes are dependent on tumor location and histopathology. Tumors of the tuberculum sella, for example, are likely to present with visual compromise given their proximity to the optic canal, and tumor dissection can further compromise vision. Gardner et al. [23] summarized their experience with 35 meningiomas including 13 tuberculum meningiomas and found no patients with visual deterioration using the endoscopic approach. Differences in outcomes between open and endoscopic approaches are difficult to discern given the relatively small series. One study using a lateral supraorbital approach showed visual deterioration in 7 of 42 patients $(17 \%)$ [24]. Using a subfrontal approach, reasonably good visual outcomes can be obtained, with one study showing that only $4.2 \%$ of patients had visual deterioration [25]. A large systematic review, however, showed no difference in visual outcomes for olfactory and tuberculum meningiomas despite improvements in gross total resection rates and reduced CSF leaks in patients with open approaches [26].

\section{Quality of Life}

The World Health Organization defined quality of life as

an individual's perception of their position in life in the context of the culture and value systems in which they live and in relation to their goals, standards and concerns. It is a broad ranging concept affected in a complex way by the person's physical health, psychosocial state, level of independence, social relationships, and their relationships to salient features of their environment [27].

This abstract concept can be difficult to quantify. Some challenges in measuring quality of life in skull base surgery include

- The multitude of domains (both physical and nonphysical) of quality of life affected by skull base tumors

- The heterogeneity of histopathology of the skull base, each of which has vastly different consequences on quality of life

- The scarcity of pathology necessitates collaborative efforts to ensure sufficiently large sample sizes

Because of these unique challenges in measuring healthrelated quality of life for skull base surgery, a unique 
instrument must be utilized with a disease-specific focus. A generic instrument such as the SF-36 may be useful in comparing quality of life of patients with skull base tumors to another unrelated disease, but this instrument has limitations comparing similar disease processes. Consider, for example, two hypothetical patients treated with an endoscopic approach, one with a pituitary adenoma and the other with a clival chordoma. Assume post-operatively that they are both able to ambulate and perform activities of daily living, but the first has no deficits while the second is left with diplopia and facial numbness. With general questions about ambulation and activities of daily living, a generic instrument like the SF-36 may not be sensitive to these changes. Capturing disease-specific domains is imperative in fully measuring disease-specific quality of life.

\section{Skull Base QOL Instruments}

A recent systematic review identified nine quality of life instruments germane to skull base surgery [28]. Of these instruments, seven related to sellar pathology and two were applicable to all skull base pathologies. Of the latter, one contained four items and did not undergo any form of psychometric testing [11]. The other, the Anterior Skull Base (ASB) Questionnaire [29], was developed using input from patients undergoing open skull base surgery, but has since been applied to patients undergoing endoscopic approaches [30]. This 35-item instrument has six domains, with one physical domain containing seven disease-specific items (appetite, taste, smell, appearance, nasal secretions, tears, eyesight). Because of the broad range of symptomatology experienced by patients with skull base pathology, the multitude of domains affected by skull base surgery, and the need for an instrument with content validity for patients undergoing endoscopic approaches, our group developed the Skull Base Inventory (SBI) [31••]. This instrument is a 41-item quality of life questionnaire generated using a composite approach of focus groups of patients who have undergone either open or endoscopic approaches, systematic review of existing instruments, and retrospective review of outcomes of 138 patients with skull base pathology. The instrument is disease-specific to skull base pathology and contains five physical sub-domains of items relating to endocrine, nasal, neurological, visual, and general physical function. A cognitive domain in the instrument captures cognitive changes experienced by patients. We used this comprehensive approach for domain and item generation to ensure the instrument had both face and content validity; however, the instrument is currently undergoing psychometric evaluation in cross-sectional and multi-institutional prospective studies.
The Anterior Skull Base Nasal Inventory-12 (ASK Nasal-12) was developed to evaluate nasal complaints following endoscopic skull base surgery [32••]. Internal consistency, test-retest reliability, concurrent validity, and discriminant validity have all been established in a cohort of 104 patients. The instrument is unidimensional and it targets a specific population-those undergoing endonasal endoscopic surgery. Other authors have used the Sinonasal Outcome Test (SNOT-22) to measure sinonasal morbidity following endoscopic skull base surgery [3, 8• 33], although it was originally intended for patients with chronic rhinosinusitis. Table 1 summarizes all relevant questionnaires for skull base surgery.

\section{Quality of Life-Endoscopic Skull Base Surgery}

The use of endoscopic endonasal approaches has provided surgeons with a new approach to skull base tumors, and for certain tumors and certain anatomic locations, offers a superior approach by minimizing brain retraction, and potential injury to vital structures. Patients undergoing endoscopic approaches seem to have a temporary decline in their quality of life followed by a return to baseline as soon as 3 months following surgery [3, 10॰]. A recent cross-sectional study of patients who were at least 6 months after endoscopic skull base surgery showed that patients experienced an improvement in physical function, but a reduction in other domains (performance, vitality, pain, emotions, specific symptoms) [30]. Interestingly, the location of the tumor (cribiform, planum, sella, clivus, maxilla) did not seem to affect quality of life, but simpler, less expanded approaches such as the transsellar approach was associated with improved quality of life. Unlike in patients who have open surgery, radiotherapy, malignancy, recurrent operations, and comorbidity did not seem to be associated with poorer QOL. However, this was a small cross-sectional study with potential for recall bias.

\section{Quality of Life-Open Skull Base Surgery}

In patients undergoing open approaches, Gil et al. [41] showed that $37 \%$ have an improvement in their overall quality of life, while $37 \%$ have no change, and $26 \%$ experienced a deterioration following open subfrontal approaches for ASB pathology. In the same study, using the ASB tool, the authors demonstrated that the presence of a malignant diagnosis, radiotherapy, old age, comorbidity, and wide resection all significantly lowered quality of life. Similar to patients undergoing endoscopic approaches, there seems to be a relative decline in quality of life followed by a gradual improvement up to 6 months to a year 
Table 1 Quality of life instruments for skull base tumors

\begin{tabular}{|c|c|c|c|c|c|}
\hline Instrument & Target population & Domains & Items & $\begin{array}{l}\text { Mode of } \\
\text { administration }\end{array}$ & Reliability and validity \\
\hline \multicolumn{6}{|c|}{ Disease-specific quality of life (Anterior Skull Base) } \\
\hline SBI $[31 \bullet \bullet]$ & $\begin{array}{l}\text { Anterior and } \\
\text { Central Skull } \\
\text { Base }\end{array}$ & $\begin{array}{l}11 \text { Endocrine nasal neurologic } \\
\text { visual general cognitive } \\
\text { emotional family financial } \\
\text { social spiritual (6 disease- } \\
\text { specific) }\end{array}$ & $\begin{array}{l}41(26 \\
\text { disease- } \\
\text { specific })\end{array}$ & Self & $\begin{array}{l}\text { Face and content validity for } \\
\text { open and endoscopic } \\
\text { (ongoing studies for further } \\
\text { reliability, validity) }\end{array}$ \\
\hline ASB [29] & $\begin{array}{l}\text { Anterior Skull } \\
\text { Base }\end{array}$ & $\begin{array}{l}6 \text { Performance, physical } \\
\text { function, vitality, pain, } \\
\text { emotions, specific symptoms } \\
\text { (1 disease-specific) }\end{array}$ & $\begin{array}{l}35(7 \\
\text { disease- } \\
\text { specific })\end{array}$ & Interviewer & $\begin{array}{l}\text { Both established for open skull } \\
\text { base (preliminary reliability } \\
\text { for endoscopic) }\end{array}$ \\
\hline MDS [11] & $\begin{array}{l}\text { Anterior Skull } \\
\text { Base }\end{array}$ & 1 & $\begin{array}{l}4 \text { (4 } \\
\text { disease- } \\
\text { specific) }\end{array}$ & Self & Not established \\
\hline \multicolumn{6}{|l|}{ Disease-specific (sinonasal) } \\
\hline ASB-Nasal $12[32 \bullet \bullet]$ & $\begin{array}{l}\text { Anterior Skull } \\
\text { Base }\end{array}$ & 1 (Nasal) & 12 & Self & Yes (for endoscopic patients) \\
\hline \multicolumn{6}{|c|}{ Disease-specific quality of life (sellar pathology) } \\
\hline AcroQOL [34] & Acromegaly & $\begin{array}{l}3 \text { Physical, psychological } \\
\text { appearance, psychological } \\
\text { relations }\end{array}$ & 22 & Self & Yes (only for acromegaly) \\
\hline QLS-H [35] & $\begin{array}{l}\text { Growth hormone } \\
\text { deficiency/ } \\
\text { hypopituitary }\end{array}$ & 2 Physical, emotional & 9 & Unclear & $\begin{array}{l}\text { Yes (only for growth hormone } \\
\text { and hypopituitary) }\end{array}$ \\
\hline Pituitary adenoma [36] & $\begin{array}{l}\text { Pituitary } \\
\text { adenomas }\end{array}$ & $\begin{array}{l}5 \text { General health, emotional, } \\
\text { social, family health, } \\
\text { physician relations }\end{array}$ & 54 & Self & $\begin{array}{l}\text { Yes (only for pituitary } \\
\text { adenoma) }\end{array}$ \\
\hline Addisons [37] & Addison's disease & 2 Physical, emotional & 36 & Unclear & Yes (for Addison's) \\
\hline QOL-AGHDA [38] & $\begin{array}{l}\text { Growth homone } \\
\text { deficiency }\end{array}$ & $\mathrm{n} / \mathrm{a}$ & 25 & Self & $\begin{array}{l}\text { Yes (for growth hormone } \\
\text { deficiency) }\end{array}$ \\
\hline HDQOL [39] & Hypopituitary & $\begin{array}{l}20 \text { Work, family, social, sex, } \\
\text { appearance, self-confidence, } \\
\text { physical, leisure, travel, } \\
\text { motivation, spiritual, society, } \\
\text { future worries, finances, } \\
\text { dependence, fussing, living } \\
\text { conditions, diet }\end{array}$ & 20 & Self & Yes (for hypopituitary) \\
\hline Cushing [40] & Cushing's disease & $\mathrm{n} / \mathrm{a}$ & 12 & Self & Yes (for Cushing's disease) \\
\hline
\end{tabular}

after surgery [41, 42••]. These disturbances in quality of life are mainly disease-specific [11].

\section{Quality of Life Comparisons by Approach}

To date there is no prospective quality of life comparison between open and endoscopic approaches. Using the ASB instrument, Abergel et al. [43••] compared patients undergoing the two approaches and showed that patients undergoing an endoscopic approach had better domain scores in physical function and impact on emotions domains. Comparisons of these groups is difficult as the questionnaires were administered at variable time points after surgery in a cross-sectional fashion, and there was significant heterogeneity between the groups with regards to histopathology, radiotherapy, and comorbidities. In comparing physical symptoms by approach, our group demonstrated that patients undergoing endoscopic approaches had a different morbidity profile than those undergoing open approaches [22]. Trends were shown for improvement in visual, neurologic, and endocrine symptoms with worsening nasal symptoms using the endoscopic approach. Future prospective multi-institutional studies are needed to help better understand the quality of life differences between surgical approaches. 


\section{Conclusion}

Maintaining quality of life for patients undergoing skull base surgery is an important treatment goal sometimes limited by the extent of disease and other factors. To date, it is not entirely clear if newer surgical approaches such as the endoscopic endonasal approach offer superior outcomes to existing open approaches. Challenges exist with regards to how to best measure and compare outcomes. New quality of life instruments are available to help better answer questions in future prospective studies.

\section{Compliance with Ethics Guidelines}

Conflict of Interest John R. de Almeida and Allan D. Vescan declare that they have no conflict of interest.

Human and Animal Rights and Informed Consent This article does not contain any studies with human or animal subjects performed by any of the authors.

\section{References}

Papers of particular interest, published recently, have been highlighted as:

- Of importance

•- Of major importance

1. - de Almeida JR, Snyderman CH, Gardner PA, Carrau RL, Vescan AD. Nasal morbidity following endoscopic skull base surgery: a prospective cohort study. Head Neck. 2011;33(4):547-51. This study examines the nasal morbidity following skull base surgery and demonstrated that over three months of nasal crusting is expected with other functional deficits.

2. Alobid I, Ensenat J, Marino-Sanchez F, et al. Impairment of olfaction and mucociliary clearance after expanded endonasal approach using vascularized septal flap reconstruction for skull base tumors. Neurosurgery. 2013;72(4):540-6.

3. McCoul ED, Anand VK, Bedrosian JC, Schwartz TH. Endoscopic skull base surgery and its impact on sinonasal-related quality of life. Int Forum Allergy Rhinol. 2012;2(2):174-81.

4. Kimple AJ, Leight WD, Wheless SA, Zanation AM. Reducing nasal morbidity after skull base reconstruction with the nasoseptal flap: free middle turbinate mucosal grafts. Laryngoscope. 2012;122(9):1920-4.

5. Rawal RB, Kimple AJ, Dugar DR, Zanation AM. Minimizing morbidity in endoscopic pituitary surgery: outcomes of the novel nasoseptal rescue flap technique. Otolaryngol Head Neck Surg. 2012;147(3):434-7.

6. Rivera-Serrano CM, Snyderman CH, Gardner P, et al. Nasoseptal "rescue" flap: a novel modification of the nasoseptal flap technique for pituitary surgery. Laryngoscope. 2011;121(5):990-3.

7. Bedrosian JC, McCoul ED, Raithatha R, Akselrod OA, Anand VK, Schwartz TH. A prospective study of postoperative symtoms in sinonasal quality of life following endoscopic skull-base surgery: dissociations based on specific symptoms. Int Forum Allergy Rhinol. 2013 Mar 20. [epub ahead of print].

8. - Sowerby LJ, Gross M, Broad R, Wright ED. Olfactory and sinonasal outcomes in endoscopic transsphenoidal skull-base surgery. Int Forum Allergy Rhinol. 2013;3(3):217-20. This study looked at olfactory outcomes using subjective tests and did not observe any olfactory deficits with middle turbinate resection for skull base surgery.

9. Georgalas C, Badloe R, van Furth W, Reinartz S, Fokkens WJ. Quality of life in extended endonasal approaches for skull base tumors. Rhinology. 2012;50(3):255-61.

10. - Pant H, Bhatki A, Snyderman CH, et al. Quality of life following endonasal skull base surgery. Skull Base. 2010;20(1):35-40. This study showed that skull base quality of life temporarily declines and improves 4-6 months after surgery in patients undergoing endoscopic approaches.

11. Palme CE, Irish JC, Gullane PJ, Katz MR, Devins GM, Bachar G. Quality of life analysis in patients with anterior skull base neoplasms. Head Neck. 2009;31(10):1326-34.

12. Kekatpure VD, Rajan GP, Patel D, Trivedi NP, ARun P, Iyer S, Kuriakos MA. Morbidity profile and functional outcome of modified facial translocation approaches for skull base tumors. Skull Base. 2011;21(4):255-60.

13. - Kassam AB, Prevedello DM, Carrau RL, et al. Endoscopic endonasal skull base surgery: analysis of complications in the authors' initial 800 patients. J Neurosurg. 2011;114(6):1544-68. This large study examined complications and neurological functional outcomes following endoscopic endonasal skull base surgery.

14. - Kono Y, Prevedello DM, Snyderman $\mathrm{CH}$, et al. One thousand endoscopic skull base surgical procedures demystifying the infection potential: incidence and description of postoperative meningitis and brain abscesses. Infect Control Hosp Epidemiol. 2011;32(1):77-83. This study, like the previous, also reported neurological deficits following skull base surgery.

15. Donald PJ. Complications in skull base surgery for malignancy. Laryngoscope. 1999;109:1959-66.

16. Kryzanksi JT, Annino DJ, Gopal H, Heilman CB. Low complication rates of cranial and craniofacial approaches to midline anterior skull base lesions. Skull Base. 2008;18:229-41.

17. Deschler DG, Gutin PH, Mamelak AN, McDermott MW, Kaplan MJ. Complications of anterior skull base surgery. Skull Base Surg. 1996;6:113-8.

18. Feiz-Erfan I, Han PP, Spetzler RF, et al. The radical transbasal approach for resection of anterior and midline skull base lesions. J Neurosurg. 2005;103:485-90.

19. Neligan PC, Mulholland S, Irish J, et al. Flap selection in cranial base reconstruction. Plast Reconstr Surg. 1996;98(7):1159-66.

20. Ganly I, Patel SG, Singh B, et al. Complications of craniofacial resection for malignant tumors of the skull base: report of an international collaborative study. Head Neck. 2005;27(6):445-51.

21. Carrabba G, Dehdashti AR, Gentili F. Surgery for clival lesions: open resection versus expanded endoscopic endonasal approach. Neurosurg Focus. 2008;25(6):E7.

22. de Almeida JR, Witterick IJ, Gullane PJ, et al. Physical morbidity by surgical approach and tumor location in skull base surgery. Head Neck. 2013;35(4):493-9.

23. Gardner PA, Kassam AB, Thomas A. Endoscopic endonasal resection of anterior cranial base meningiomas. Neurosurgery. 2008;63(1):36-52.

24. Romani R, Laakso A, Kangasniemi M, Niemela M, Hernesniemi J. Lateral supraorbital approach applied to tuberculum sellae meningiomas: experience with 52 consecutive patients. Neurosurgery. 2012;70(6):1504-18.

25. Jang WY, Jung S, Jung TY, Moon KS, Kim IY. The contralateral subfrontal approach can simplify surgery and provide favorable visual outcome in tuberculum sellae meningiomas. Neurosurg Rev. 2012;3(4):601-7.

26. Komotar RJ, Starke RM, Raper DMS, Anand VK, Schwartz TH. Endoscopic endonasal versus open transcranial resection of 
anterior midline skull base meningiomas. World Neurosurg. 2012;77(5):713-24.

27. World Health Organization. Rehabilitation after cardiovascular diseases, with special emphasis on developing countries: report of a WHO expert committee. Geneva: WHO; 1993. WHO Technical Report Series 831.

28. de Almeida JR, Witterick IJ, Gullane PJ, et al. Quality of life instruments for skull base pathology: systematic review and methodologic appraisal. Head Neck. 2012 Sept 18 [epub ahead of print].

29. Gil Z, Abergel A, Spektor S, et al. Development of a cancerspecific anterior skull base quality of life questionnaire. J Neurosurg. 2004;100:813-9.

30. Cavel O, Abergel A, Margalit N, Fliss DM, Gil Z. Quality of life following endoscopic resection of skull base tumors. J Neurol Surg B. 2012;73(2):112-6.

31. • de Almeida JR, Vescan AD, Gullane PJ, Gentili F, Lee JM, Lohfeld L, Ringash J, Thoma A, Witterick IJ. Development of a disease-specific quality of life questionnaire for anterior and central skull base pathology - the skull base inventory. Laryngoscope. 2012;122:1933-1942. This study described a novel quality of life questionnaire for skull base surgery which has content validity both for open and endoscopic approaches.

32. •• Little AS, Kelly D, Milligan J, et al. Prospective validation of a patient-reported nasal quality of life tool for endonasal skull base surgery: the Anterior Skull Base Nasal Inventory-12. J Neurosurg. 2013 May 10 [epub ahead of print]. This study describes a new instrument for nasal morbidity following endoscopic skull base surgery.

33. Ransom ER, Doghramji L, Palmer JN, Chiu AG. Global and disease specific health related quality of life after complete endoscopic resection of anterior skull base neoplasms. Am J rhinol Allergy. 2012;26(1):76-9.

34. Badia X, Webb SM, Prieto L, Lara N. Acromegaly quality of life questionnaire (AcroQOL). Health Qual life Outcomes. 2004;2:13.

35. Herschbach P, Henrich G, Strasburger CJ, Feldmeier H, Marin F, Attanasio AM, Blum WF. Development and psychometric properties of a disease-specific quality of life questionnaire for adult patients with growth hormone deficiency. Eur J Endocrinol. 2001;145:255-65.

36. Kan P, Cusimano M. Validation of a quality of life questionnaire for patients with pituitary adenoma. Can J Neurol Sci. 2006;33:80-5.

37. Lovas K, Curran S, Oksnes M, Husebye ES, Huppert FA, Chatterjee KK. Development of a disease-specific quality of life questionnaire in Addison's disease. J Clin Endocrinol Metab. 2010;95(2):545-51.

38. McKenna SP, Doward LC, Alonso J, Kohlmann T, Niero M, Prieto L, Wiren L. The QoL-AGHDA: an instrument for the assessment of quality of life in adults with growth hormone deficiency. Qual Life Res. 1999;8:373-83.

39. McMillan CV, Bradley C, Gibney J, Russell-Jones DL, Sonksen PH. Preliminary development of the new individualized HDQOL questionnaire measuring quality of life in adult hypopituitarism. J Eval Clin Pract. 2006;12(5):501-14.

40. Webb SM, Badia X, Barahona MJ, Colao A, Strasburger CJ, Tabarin A, van Aken MO, Pivonella R, Stalla G, Lamberts SWJ, Glusman JE. Evaluation of health-related quality of life in patients with Cushing's syndrome with a new questionnaire. Eur J Endocrinol. 2008;158:623-30.

41. Gil Z, Abergel A, Spektor S, et al. Quality of life following surgery for anterior skull base tumors. Arch Otolaryngol Head Neck Surg. 2003;129(12):1303-9.

42. • Abergel A, Fliss DM, Margalit N, Gil Z. A prospective evaluation of short-term health-related quality of life in patients undergoing anterior skull base surgery. Skull Base. 2010;20(1):27-33. This study describes quality of life changes following skull base surgery.

43. •• Abergel A, Cavel O, Margalit N, Fliss DM, Gil Z. Comparison of quality of life after transnasal endoscopic vs. open skull base tumor resection. Arch Otolaryngol Head Neck Surg. 2012;138(2):142-147. This study compares open and endoscopic skull base surgery in a cross-sectional fashion and notes that endoscopic surgery is significantly better in some areas. 